\title{
The San Luigi Gonzaga Hospital (Turin, Italy) experience: improving blood and urine culture pre-analytical quality by shared protocols
}

\author{
Angela Samiolo, ${ }^{1}$ Elena Ardizzi, ${ }^{2}$ Angela Ardizzola, ${ }^{3}$ Ornella Bianco, ${ }^{1}$ Anna Rita De Luigi, ${ }^{4}$ Paola Lovera, \\ Stefania Pelassa, ${ }^{4}$ Paola Silvaplana, ${ }^{5}$ Giuseppina Viberti, ${ }^{1}$ Giuseppe De Renzi ${ }^{1}$ \\ ${ }^{1}$ SCDO Laboratorio di Patologia Clinica e Microbiologia, Azienda Ospedaliera Universitaria San Luigi Gonzaga, \\ Orbassano; ${ }^{2}$ SCDO Medicina e Chirurgia d'Accettazione e d'Urgenza, Azienda Ospedaliera Universitaria San Luigi \\ Gonzaga, Orbassano; ${ }^{3}$ AOU Città della Salute e della Scienza, Laboratorio Analisi Biochimica Clinica, Presidio \\ Ospedale Infantile Regina Margherita, Torino; ${ }^{4}$ SC Direzione Professioni Sanitarie, Azienda Ospedaliera Universitaria \\ San Luigi Gonzaga, Orbassano; ${ }^{5}$ Direzione Medica di Presidio, SS Unità Prevenzione Rischio Infettivo (UPRI), \\ Azienda Ospedaliera Universitaria San Luigi Gonzaga, Orbassano, Italy
}

\section{Summary}

Background and aims: Reduction in the number of blood culture and urine culture contamination samples.

Materials and methods: We have designed a partly retrospective and partly prospective observational study. On one hand, we have been striving for the creation, dissemination and promotion of shared operational rules in all departments/hospital services to improve the quality of the levy; on the other hand, we analysed data. We considered blood cultures and urine cultures analysed in the laboratory from March to August 2015, and from March to August 2016. The data were processed with $\mathrm{R}$ and the incidence of contaminated samples was calculated by dividing the number

Correspondence: Giuseppe De Renzi, Via Genova 122, 10126, Torino, Italia.

Tel.: +39.338.5882519 - Fax: +011.9026629.

E-mail: g.derenzi@sanluigi.piemonte.it; pinoderenzi@hotmail.it

Key words: Blood culture; Urine culture; Contamination rate; Nursing education; Preanalytical quality.

Contributions: the authors contributed equally.

Conflict of interest: the authors declare no potential conflict of interest.

Poster presentation: part of this paper was presented at XLV Congresso Nazionale AMCLI 2016 - Rimini, Italy, 6-9 Novembre 2016. Poster n ${ }^{\circ}$ P077.

Received for publication: 28 January 2017.

Revision received: 25 March 2017.

Accepted for publication: 26 March 2017.

CC Copyright A. Samiolo et al., 2017

Licensee PAGEPress, Italy

Microbiologia Medica 2017; 32:6602

doi:10.4081/mm.2017.6602

This article is distributed under the terms of the Creative Commons Attribution Noncommercial License (by-nc 4.0) which permits any noncommercial use, distribution, and reproduction in any medium, provided the original author(s) and source are credited. of blood cultures/urine cultures contaminated by the total. The results of 2015 and 2016 were compared by $\chi^{2}$. To highlight the possible differences between departments and identify those at higher risk of contamination, the data of each year were stratified dividing departments into five groups: Medicine, Surgery, Critical Area, Specialties and ER. To assess the strength of the association, a risk analysis was carried out using the risk ratio (RR). The RR was calculated by dividing the contamination rates of 2015 by the those of 2016. The value of $\alpha$ was set at 0.05 .

Results: After implementation of the shared protocols, blood culture contamination was substantially reduced $(-56.8 \%$, $\mathrm{P}=1.783 \mathrm{e}-05)$, confirmed by an RR of 2.2 (95\%CI: $1.54 \pm 3.27$ ). The evidence is strengthened by the finding of a lower number of isolates belonging to the group of possible contaminants $(-32.7 \%$, $\mathrm{P}=2.042 \mathrm{e}-07)$ and confirmed by an RR of 1.5 (95\% CI: $1.27 \pm 1.73)$. Urine culture data analysis showed no change in the incidence of contamination between 2015 and $2016(\mathrm{P}=0.8808)$, as confirmed by a non-informational RR ( $95 \% \mathrm{CI}: 0.62 \pm 1: 46)$. Even the analysis of the individual areas showed no change in the two semesters, as confirmed by the risk analysis that does not show any association between outcome and group.

Conclusions: The results confirm the value of multidisciplinary work and encourage us to continue the path of standardisation and updating of the sampling procedures, as well as the prospective monitoring and comprehensive analysis of the data collected for longer time intervals.

\section{Introduction}

Blood and urine cultures represent an essential tool for the healthcare professional as a means of detecting the dangerous presence of living organisms in the bloodstream and in the urine $(19,21,26,46)$. A positive test can suggest a definitive diagnosis, enable targeting of the therapy against the specific organism(s) in question, and provide prognostic value. Like any test, however, false-positive results can limit the utility of such a tool. False positives arise due to contamination, which occurs when organisms that are not actually present in a sample grow in culture. Ambiguous culture results often lead to diagnostic uncertainty in clinical management and are associated with increased health care costs due to unnecessary treatment and testing $(7,34,38)$. In a process aimed at improving the quality of service provided to 
users, a multidisciplinary group named Appropriateness in Microbiology was established in October 2015 in the hospital San Luigi Gonzaga (Orbassano, Italy), with the aim of minimising errors in the pre-analytical phase of sample processing. The working group designed an observational study, in part retrospective and in part prospective, to reduce the number of contaminated samples by improving the quality of the levy through the dissemination and promotion of shared operational rules in all departments/hospital services.

\section{Materials and Methods}

In the medical literature, teamwork was related to reducing contaminations $(2,7,16,35)$. Our team was multidisciplinary and included three nursing coordinators, a nursing tutor, a physician and a biologist of the Clinical Microbiology Laboratory and a graduate student in Biomedical Laboratory Techniques. Teamwork was considered an essential component of our initiative. We reviewed the literature to identify best practices related to blood culture and urine culture collection. It was essential for us to use intervention strategies that had been proven to be effective in overcoming barriers to the ones we had identified in achieving optimal specimen collection. We also used tailored strategies to meet our specific needs. Our target was the reduction in the number of blood culture and urine culture contamination samples. To achieve these targets, we put in place multi-target strategies: on the one hand, the group worked at the creation, dissemination and promotion of operative rules shared in all departments/hospital services; on the other hand, it conducted laboratory work to define criteria to precisely evaluate contamination, estimate the size of the problem and assess the effectiveness of the intervention.

\section{Planning the intervention}

At first, we investigated arrangements of the levy by the nursing staff. We chose the focus groups as the best technical quality survey. Focus groups were held in December 2015, and the departments were divided into four groups per care area: Medicine, Surgery, Critical Area and Specialties. Each focus was attended by at least two members of the group, the moderator and the observer. We used common questions about the sampling techniques. In
January 2016, the group committed to transcribing the discussions, evaluating the results, preparing the new protocols and planning the next phase: the educational program. Training meetings were planned at the Corporate Training Centre, also involving those departments/services which did not take part in the focus groups, but who occasionally performed both blood cultures that urine culture. On March 1st, the new application rules came into force, and the observation period officially began. Within six months, we had promoted the guidelines application with posters displayed in the departmental infirmaries illustrating the correct withdrawal method. The evaluation of protocols application took place qualitatively by carrying out a new series of focus groups at the end of the observation period.

\section{Data analysis}

We included only samples whose levy was nursing expertise: blood samples and urine samples obtained by urethral catheterisation. We considered the blood cultures and urine cultures analysed in the laboratory in semesters from March to August 2015, and from March to August 2016. We chose this time for logistic reasons: new protocols were presented in early February 2016, therefore we decided to set the observation period from 1 March to 31 August six months in total. To avoid the confounding presence (seasonal pattern of infection and type of nosocomial microorganisms) and increase the efficiency of statistical tests, we decided to compare the contamination rate detected in 2016 with those of the same period last year.

Based on different approaches found in literature $(3,4,7,11,18,19,33,36)$, we used the criteria of contamination listed in Table 1.

Blood cultures were processed using BD BACTEC FX system. It was standard practice to collect two sets from two different peripheral veins (each set included an aerobic and an anaerobic bottle) and two sets from two different central venous catheter lumens for patients with a central line. Urine cultures were processed using URO-QUICK HB\&L 4046 system. For identification and susceptibility testing the BD Phoenix ${ }^{\mathrm{TM}}$ System was used. If the instrument failed the analysis, we proceeded manually using API ${ }^{\circledR}$ galleries for identification and the Kirby-Bauer method for susceptibility testing, in compliance with the EUCAST guidelines.

The data were processed with $\mathrm{R}$ and the incidence of contaminated samples was calculated by dividing the number of blood

Table 1. Criteria for determining contamination.

\begin{tabular}{|c|c|}
\hline Blood culture & Urine culture \\
\hline $\begin{array}{l}\text { Contaminating organisms: CoNS, Bacillus spp., Corynebacterium spp., } \\
\text { Propionibacterium spp., Micrococcus, viridans streptococci, environmental } \\
\text { germs }\end{array}$ & $\begin{array}{l}\text { Contaminating organisms: Lactobacillus spp., Neisseria spp., } \\
\text { Staphylococcus spp., anaerobes, diphtheroid germs, viridans streptococci }\end{array}$ \\
\hline $\begin{array}{l}\text { Blood cultures containing one or more microorganisms belonging to the } \\
\text { environmental/contaminant group in a single bottle of a series or in a single } \\
\text { set of a series are to be considered contaminated }\end{array}$ & $\begin{array}{l}\text { Urine cultures with two germs, one with loads below } 105 \text { CFU are to be } \\
\text { considered contaminated. The identification and susceptibility testing should } \\
\text { be performed only by the germ called effective }\end{array}$ \\
\hline $\begin{array}{l}\text { Blood cultures containing a true pathogen together with one or more germs } \\
\text { of environmental/contaminant group in a single bottle of a series or in a single } \\
\text { set of a series are to be considered contaminated }\end{array}$ & $\begin{array}{l}\text { Urine cultures with two germs with equal charge or greater to } 105 \mathrm{CFU} \text { are to } \\
\text { be considered contaminated if one of the two microorganisms belong to the } \\
\text { group of contaminants, otherwise they are to be considered positive }\end{array}$ \\
\hline $\begin{array}{l}\text { The presence of one or more microorganisms belonging to the environmental/ } \\
\text { contaminant group in all of a series set, in the absence of other clinical } \\
\text { information, is to be evaluated as possible contamination }\end{array}$ & $\begin{array}{l}\text { Urine cultures with more than two germs with loads equal to or greater than } \\
105 \text { CFU are to report as polymicrobial and are to be considered contaminated. } \\
\text { They should not be executed for identification, or susceptibility testing } \\
\text { Urine cultures with more than two germs with loads below } 105 \text { CFU are to } \\
\text { report as poor not significant flora and are to be considered contaminated. } \\
\text { They should not be executed for identification, or susceptibility testing }\end{array}$ \\
\hline
\end{tabular}


cultures/urine culture contaminated by the total. The results of 2015 and 2016 were compared by $\chi^{2}$. To highlight the possible differences between departments and identify those most at risk of contamination, the data from each year were stratified, dividing departments into five groups: Medicine, Surgery, Critical Area, Specialties and ED. To assess the strength of the association, a risk analysis was carried out using the risk ratio (RR). The RR was calculated by dividing the contamination rates in 2015 by the those in 2016. The value of $\alpha$ was set at 0.05 .

\section{Results}

\section{Blood cultures}

In 2015, the laboratory received 1262 requests for a total of 3065 sets and 6130 bottles. In 2016 the requests were 1080 for a total of 2146 sets and 4292 bottles. In both semesters, patients undergoing blood culture had a mean age of 65 years with a median of 68 years. Males were $58 \%$ and females $42 \%$. The incidence of contaminated samples in the two years is shown in Figure 1. The outcome was classified according to four modes.

Negative: blood culture in which no microorganism was identified (in green).

True positive: blood culture in which a pathogen was identified (in yellow).

Contaminated: blood culture that meets the defined criteria for contamination (in red).

Possibly contaminated: blood culture that is difficult to classify based on clinical and laboratory information (in orange).

In 2016 there was a reduction of $56.8 \%$ in the number of contaminated samples, starting from $7.4 \%$ in 2015 and reaching $3.2 \%$ in 2016 (X-squared $=18.408, \mathrm{df}=1, \mathrm{P}=1.783 \mathrm{e}-05, \quad 95 \% \mathrm{CI}$ $0.02 \pm 0.06$ ). The risk ratio (RR), standardized by department, was $2.2(95 \%$ CI 1.54 \pm 3.27$)$. The incidence of contamination in 2016 was $3.2 \%$. We made a Z-test to verify if the incidence was like that proposed by the CLSI $(\leq 3 \%)$. The test result was: $z=0.4$, P-value $\alpha 1 / 2=0.344$.

Table 2 shows the germs isolated from blood cultures during the two half-years.

The pathogens most represented are Staphylococcus aureus, Escherichia coli and Candida albicans accounting for $36.1 \%$ of the insulation in 2015 and $44.4 \%$ of the insulation in 2016 . The germs defined as possible contaminants were identified in $39.5 \%$ of the positive samples in 2015 and $26.6 \%$ of the positive samples in 2016 [(-32.7\%, X-squared $=26,993, \mathrm{df}=1, \mathrm{P}=2.042 \mathrm{e}-07$ (95\%CI: $0.08 \pm 0.18), \mathrm{RR}=1.5$, (95\%CI: $1.27 \pm 1.73)]$.

Stratifying the results for healthcare area and focusing attention exclusively on the positive samples, we obtain a graph as shown in Figure 2.

Table 3 summarizes the results of $\chi^{2}$-test and the RR for the different care areas, comparing the contamination rates in 2015 and 2016.

Table 2. Germs isolated from blood cultures during the 2 half years.

\begin{tabular}{lcc} 
Blood culture & $2015(\%)$ & $2016(\%)$ \\
Positive & 60.5 & 73.4 \\
S. aureus & 14.7 & 13.0 \\
Other G+ & 8.2 & 9.0 \\
E. coli & 18.2 & 28.5 \\
Other G- & 10.4 & 14.7 \\
C. albicans & 3.2 & 2.9 \\
Other MICETI & 5.8 & 5.3 \\
Possibly contaminated & 39.5 & 26.6 \\
S. epidermidis & 17.3 & 12.6 \\
Other CoNS & 16.9 & 7.0 \\
Others & 5.3 & 7.0 \\
\hline
\end{tabular}

2015

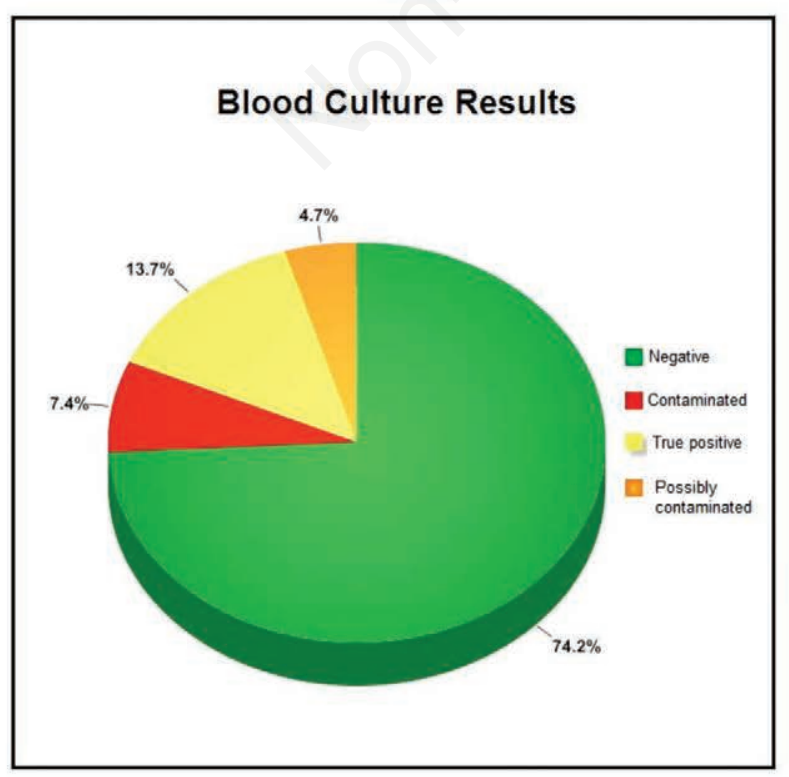

2016

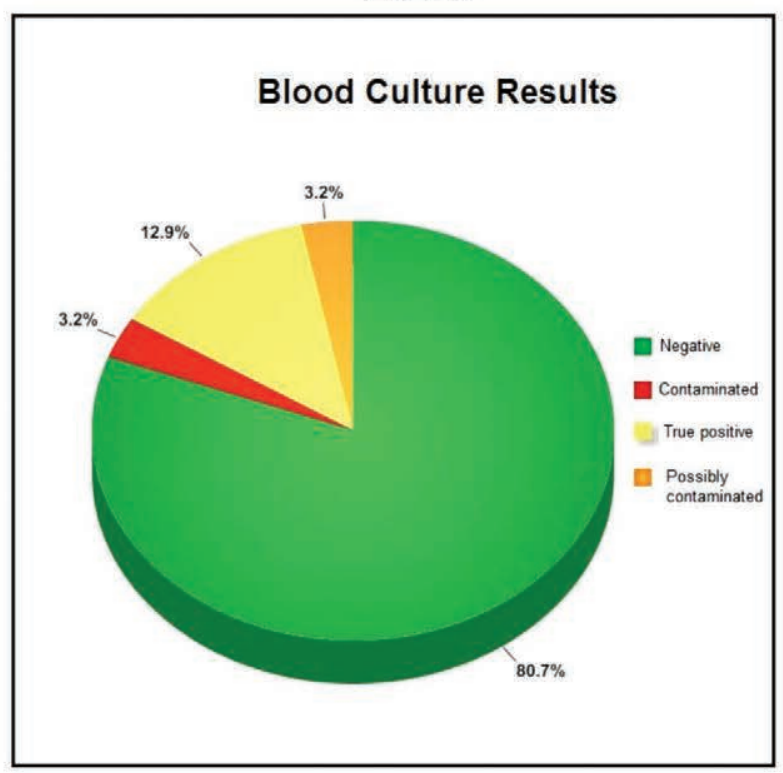

Figure 1. Blood culture results in 2015 and 2016 compared. 


\section{Urine cultures}

In 2015 the laboratory analysed 571 samples of catheter urine, in 2016 the samples were 441. In both semesters, patients undergoing urine culture had a mean age of 74 years with a median of 76.5 years. Males were $55 \%$ and females $45 \%$. The incidence of contaminated samples in the two years is shown in Figure 3. The outcome was classified in three ways.
Negative: urine culture in which no microorganism was identified (in green).

True positive: urine culture in which a pathogen was identified (in yellow).

Contaminated: urine culture that meets the defined criteria for contamination (in red).

In 2016 there has been a slight increase in the number of con-
2015

Positive Blood Culture Results

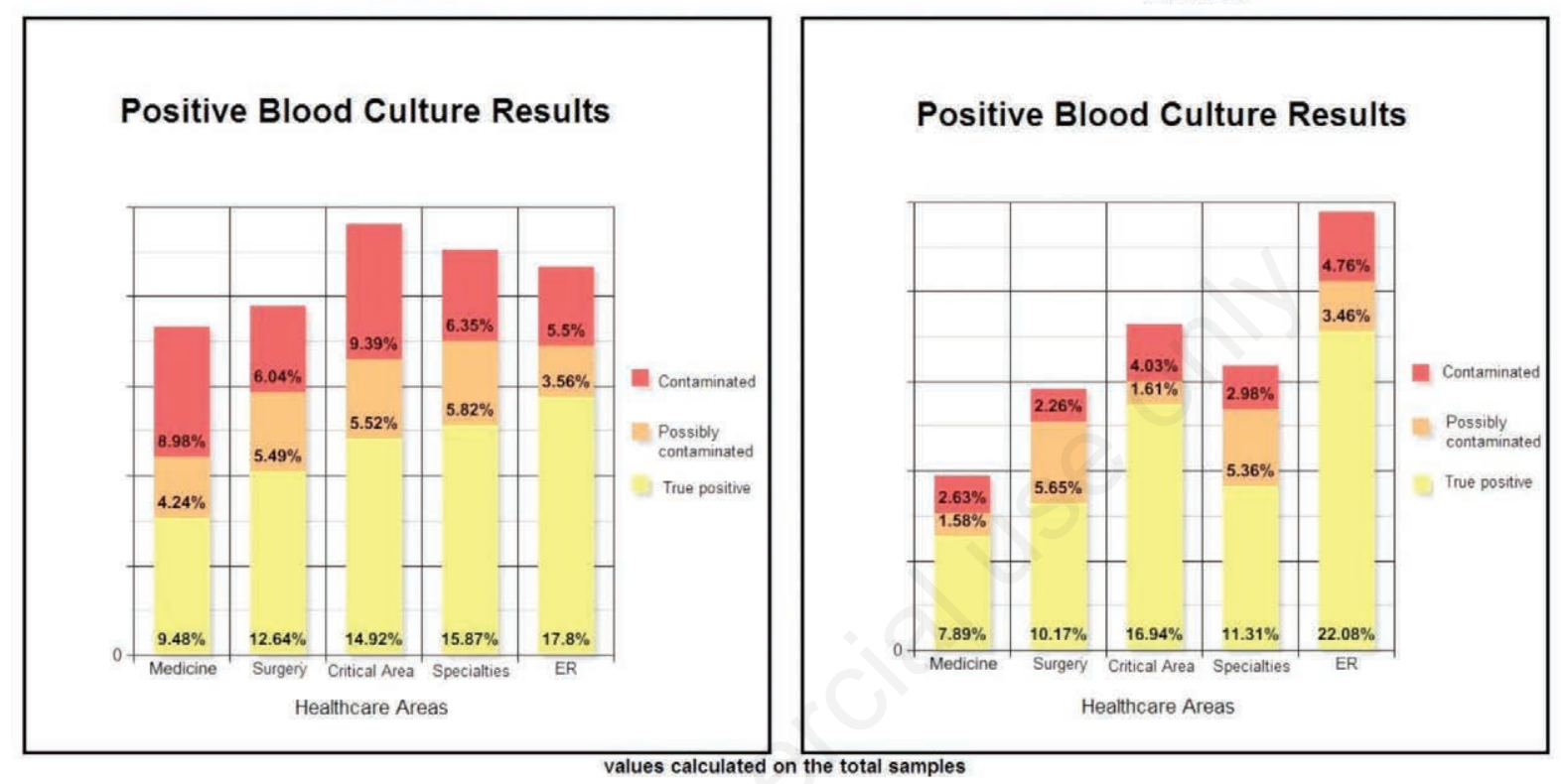

\section{Positive Blood Culture Results}

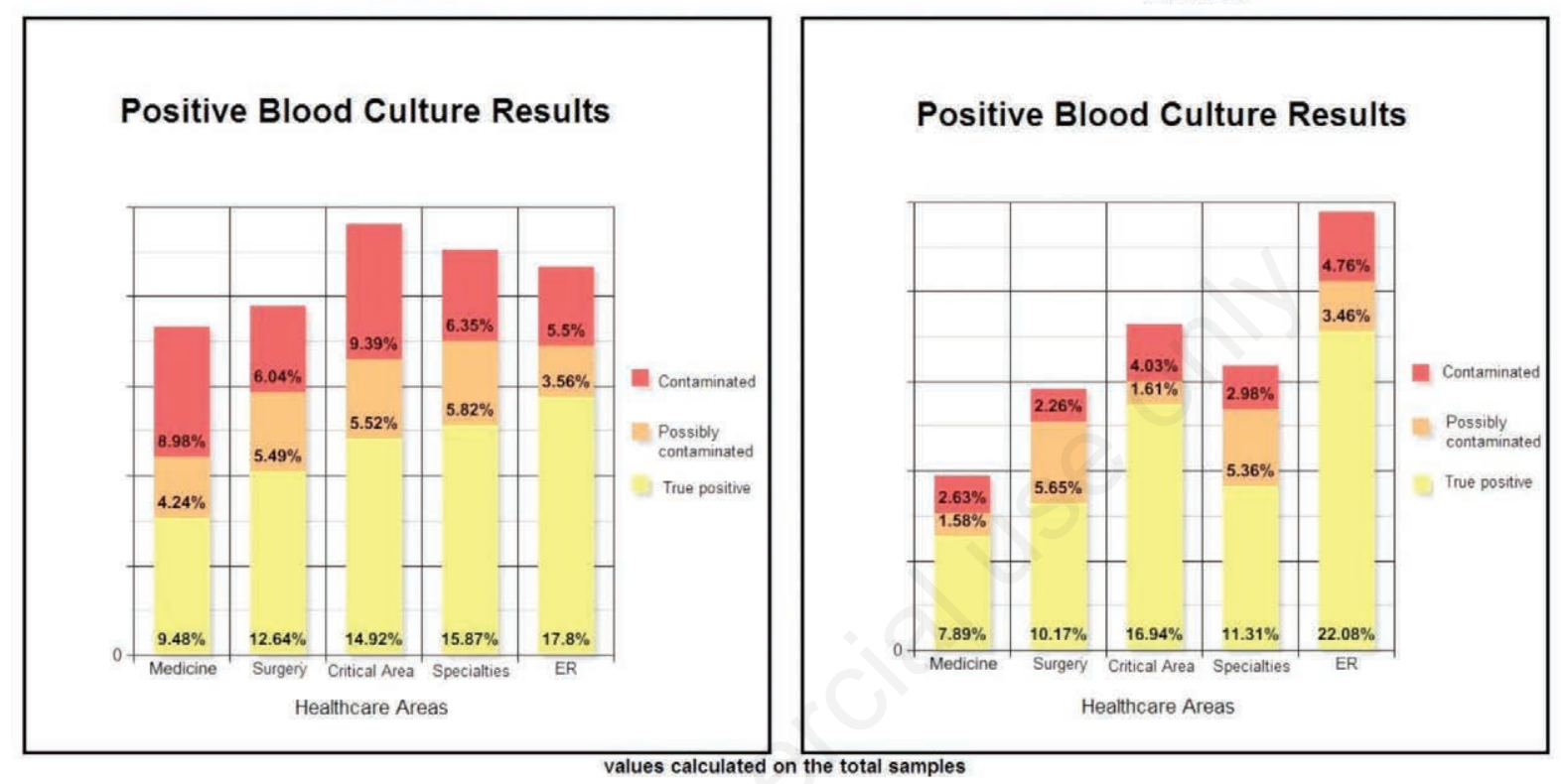

2016

Figure 2. Positive blood culture results for healthcare area.

2015

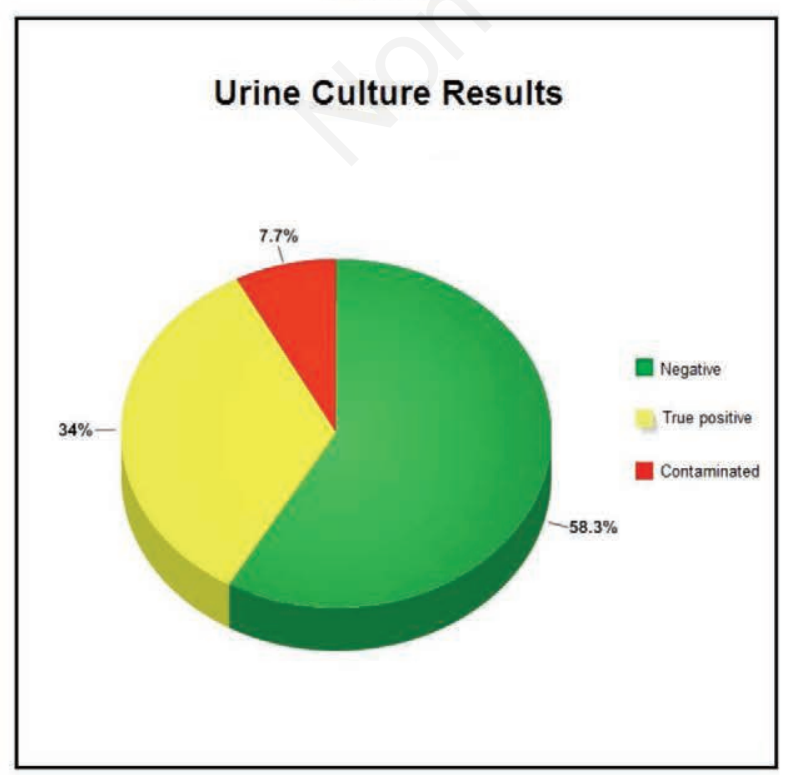

2016

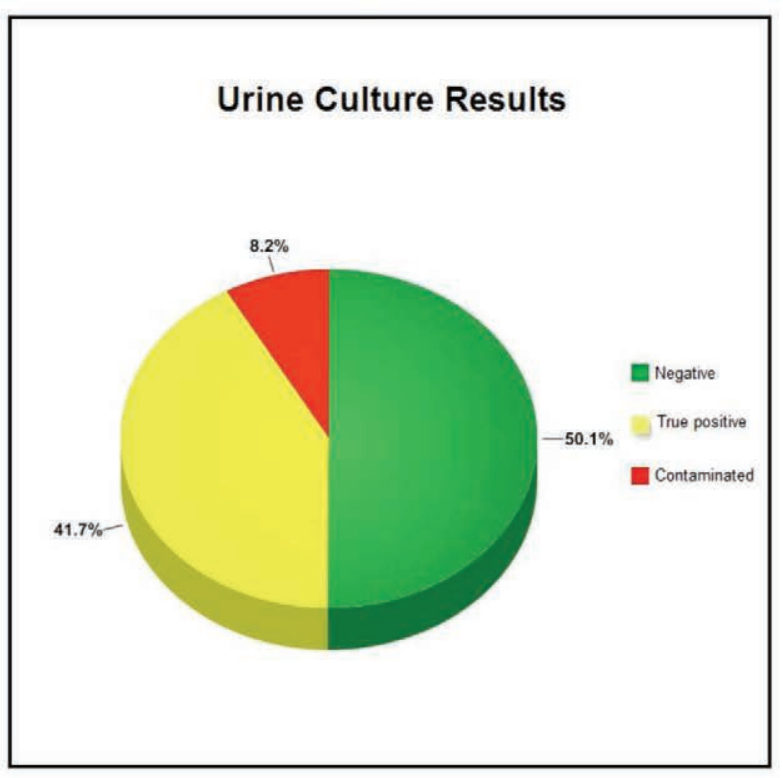

Figure 3. Urine culture results in 2015 and 2016 compared. 
taminated samples, $(+6.5 \%)$. In 2015 the incidence was $7.7 \%$ and in 2016 was $8.2 \%$ (X-squared $=0.022, \mathrm{df}=1, \mathrm{P}=0.8808,95 \% \mathrm{CI}$ : $0.04 \pm 0.03)$. The RR, standardized by department, was 0.96 (95\%CI: $0.62 \pm 1.46)$. Stratifying the results for healthcare and focusing attention exclusively on the positive samples, we obtained a graph as shown in Figure 4.

Table 4 summarizes the results of $\chi^{2}$-test and the RR for the different care areas, comparing the contamination rates in 2015 and 2016.

\section{Discussion}

\section{Blood cultures}

Data analysis shows a real reduction of contaminated samples $(-56.8 \%, \mathrm{P}=1.783 \mathrm{e}-05)$, confirmed by a $\mathrm{RR}$ of $2.2(95 \% \mathrm{CI}$ : $1.54 \pm 3.27)$. The evidence is strengthened by a lower number of isolates belonging to the group of possible contaminants $(-32.7 \%$, $\mathrm{P}=2.042 \mathrm{e}-07)$ and confirmed by an RR of 1.5 (95\%CI: $1.27 \pm 1.73)$.

Table 3. Blood culture contamination rates in 2015 and 2016 compared.

\begin{tabular}{|c|c|c|c|c|c|c|c|}
\hline Care Areas & $\begin{array}{l}\text { Contamination } \\
\text { rates } 2015(\%)\end{array}$ & $\begin{array}{l}\text { Contamination } \\
\text { rates } 2016(\%)\end{array}$ & $\begin{array}{c}x^{2} \\
(\mathrm{df}=1)\end{array}$ & $P$ & $95 \% \mathrm{CI}$ & $\begin{array}{c}\text { RR } \\
(2015 / 16)\end{array}$ & $95 \% \mathrm{CI}$ \\
\hline Medicine & 8.98 & 2.63 & 13.054 & 0.0003 & $0.028-0.098$ & 3.41 & $1.72-6.78$ \\
\hline Surgery & 6.04 & 2.26 & 2.333 & 0.13 & $0.008-0.084$ & 2.67 & $0.87-8.24$ \\
\hline Critical area & 9.39 & 4.03 & 2.408 & 0.12 & $0.008-0.115$ & 2.33 & $0.88-6.15$ \\
\hline Specialities & 6.35 & 2.98 & 1.549 & 0.21 & $0.015-0.082$ & 2.13 & $0.77-5.93$ \\
\hline ER & 5.50 & 4.76 & 0.04 & 0.85 & $0.033-0.048$ & 1.15 & $0.55-2.42$ \\
\hline
\end{tabular}

Table 4. Urine culture contamination rates in 2015 and 2016 compared.

\begin{tabular}{|c|c|c|c|c|c|c|c|}
\hline Care Areas & $\begin{array}{l}\text { Contamination } \\
\text { rates } 2015(\%)\end{array}$ & $\begin{array}{l}\text { Contamination } \\
\text { rates } 2016(\%)\end{array}$ & $\begin{array}{c}\chi^{2} \\
(d f=1)\end{array}$ & $P$ & $95 \% \mathrm{CI}$ & $\begin{array}{c}\text { RR } \\
(2015 / 16)\end{array}$ & $95 \% \mathrm{CI}$ \\
\hline Medicine & 9.15 & 6.52 & 0.374 & 0.54 & $-0.042-0.095$ & 1.40 & $0.63-3.14$ \\
\hline Surgery & 7.04 & 9.59 & 0.063 & 0.80 & $-0.129-0.078$ & 0.73 & $0.24-2.20$ \\
\hline Critical area & 6.90 & 5.65 & 0.046 & 0.83 & $-0.047-0.072$ & 1.22 & $0.50-2.94$ \\
\hline Specialities & 7.64 & 12.26 & 1.019 & 0.31 & $-0.130-0.038$ & 0.62 & $0.29-1.33$ \\
\hline
\end{tabular}

\section{5}

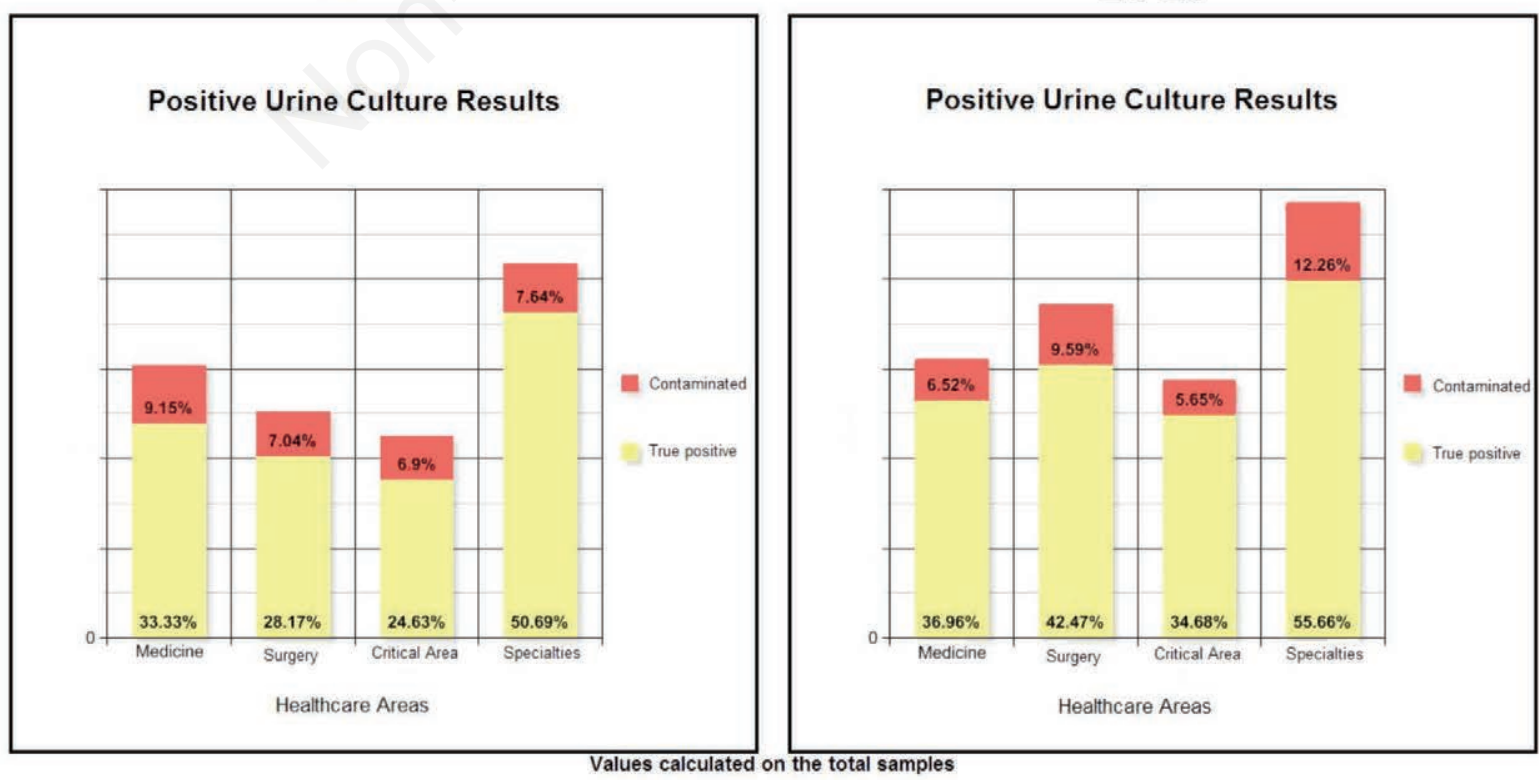

Figure 4. Positive urine culture results for healthcare area. 
Since the presence of a contaminant in a sample depends solely on the implementing rules of the levy, it is reasonable to assume that the reduction in the incidence of contamination in 2016 was due to an increase in withdrawals made properly. The moderate strength of association could be due to the short duration of observation (six months). Analyses carried out over the long term could provide more effective results. Changes in working habits of nurses from 2015 to 2016 have emerged during the focus groups. Before the introduction of the new protocols, there was a discrepancy in the execution of the sampling technique, not only between the different areas, but also between departments in the same area and between operators of the same department. The criticality adhered to four main aspects: the disinfection of the bottle cap immediately prior to the withdrawal (the cap was incorrectly considered sterile), the removal of the first quantity of blood drawn from CVC (quantity having the highest bacterial concentration), the number of sets taken (the number of sets affect the sensitivity of the method), and the storage conditions (blood cultures should be stored at room temperature, however in some departments they were kept in the fridge). The second series of focus groups, conducted at the end of the observation period, showed a more rigorous adherence to guidelines, with greater attention to disinfection of bottle caps, the conservation of the first amount of blood drawn from CVC and the immediate dispatch of the bottles in the laboratory after the execution of the levy. Interestingly, Medicine is the only group that showed a significant difference between 2015 and 2016 $(\mathrm{P}=0.0003, \mathrm{RR}=3.4,95 \% \mathrm{CI}: 1.72 \pm 6.78)$. The other groups had a reduction in contamination rates, but not enough to be considered important. Again, the shortness of the observation period has limited the effectiveness of the new application rules: in work that involves all hospital units, uniform guidelines for all staff involved in the execution of withdrawals takes time, as time is required to change work habits consolidated over the years. However, the fact that the contamination trend is downward in all departments and targets to reduce the incidence of contamination, within the limits proposed by the CLSI, were reached after only six months $(\mathrm{z}=0.4$, P-value $\alpha 1 / 2=0.344$ ), should serve as a strong incentive to continue in the direction of the pre-analytical improvement.

\section{Urine cultures}

Data analysis showed no change in the incidence of contamination between 2015 and $2016(\mathrm{P}=0.8808)$, as confirmed by a noninformational RR ( $95 \% \mathrm{CI}$ : $0.62 \pm 1.46)$. Even the analysis of the individual areas showed no change in the two years, as confirmed by the analysis of risk, which does not show any association between outcome and group. This result is not surprising: the focus groups did not reveal any critical issues in the implementation of the levy from catheter urine culture and the participants knew the correct technique even before the introduction of the new protocols. Evidently, the problem of contamination in urine culture is related to some other aspect of the pre-analytical phase which should be better investigated and studied. The study conducted by the College of American Pathologists in 2008 showed no significant differences in the incidence of contamination to the previous study, conducted ten years ago, in $1998(4,42)$. Most of the institutions are placed in the range of contamination 5-9\%, in line with that seen in our hospital $(8.2 \%)$. Another study described as the problem of contamination depended mainly on refrigeration after sampling (26), especially if the sample was not sent immediately to the laboratory. In fact, the problem of preservation also arose during the focus: it is a common habit to keep the sample at room temperature, although in most cases it will be sent immediately to the laboratory. In fact, the time of the arrival in the laboratory is far from immediate. In the morning, around 8:00, the transport work- ers visit all departments to collect samples for delivery to the laboratory, taking about an hour. This means that the urine samples, which are generally emitted around 7:00, do not arrive in the laboratory before 9:00, which promotes the proliferation of contaminating flora. It is evident that there is a necessity for the study and formulation of new strategies of intervention, aimed primarily at increasing the quality of preservation of the samples for urine culture, in order to improve the reliability of the levy intended for this type of analysis.

The study conducted by the group Appropriateness in Microbiology arises in Italy as one of the first attempts to study the blood culture and urine culture preanalytical quality, using as research methodology the evaluation of shared protocols' application by nursing staff.

This is one of the few studies concerning blood cultures to involve an entire hospital environment, and to stratify the results per consistent care areas. Concerning urine culture, it is one of the first attempts to address specifically the problem of contamination in patients with bladder catheters and adherence to guidelines for this type of withdrawal. The limitations encountered are the short period of observation and the lack of a control group, which could have provided more effective results.

\section{Conclusions}

The research team has identified prospects that could give continuity to An Appropriateness Project in Microbiology: the evaluation of the economic benefit for the Hospital arising from the reduction of contaminants; the study of urine culture contamination, with attention to the stages of preservation and transport; the study of the prescriptive appropriateness for both the examinations.

In conclusion, the results confirm the value of multidisciplinary work and encourage us to continue the path of standardisation and updating of the sampling procedures, as well as monitoring and more comprehensive analysis of the data collected in the long run.

\section{References}

1. Adams AS, Soumerai SB, Lomas J, Ross-Degnan D. Evidence of self-report bias in assessing adherence to guidelines. Int $\mathrm{J}$ Qual Health Care 1999;11:187-92.

2. Al-Hamad A, Al-Ibrahim M, Alhajhouj E, et al. Nurses' competency in drawing blood cultures and educational intervention to reduce the contamination rate. J Infect Publ Health 2016;9:66-74.

3. Boyce JM, Nadeau J, Dumigan D, et al. Obtaining blood cultures by venipuncture versus from central lines: impact on blood culture contamination rate and potential effect on central line associated bloodstream infection reporting. Infect Control Hosp Epidemiol 2013;34:1042-7.

4. Bekeris LG, Jones BC, Walsh K, Wagar A, Urine culture contamination: a college of american pathologists q-probes study of contaminated urine cultures in 127 laboratories. Arch Pathol Lab Med 2008;132:913-7.

5. Blake DR, Doherty LF, Effect of perineal cleansing on contamination rate of mid-stream urine culture. J Pediatr Adolesc Gynecol 2006;19:31-4.

6. Bouza E, Sousa D, Munoz P, et al. Bloodstream infections: a trial of the impact of different methods of reporting positive blood cultures results. Clin Infect Dis 2004;39:1161. 
7. Bowen CM, Coleman T, Cunningham D, Reducing blood culture contaminations in the emergency department: it takes a team. J Emerg Nurs 2016;42:306-11.

8. Burd EM, Kehl KS. A critical appraisal of the role of the clinical microbiology laboratory in the diagnosis of urinary tract infections. J Clin Microbiol 2011;49:34-8.

9. Clinical and Laboratory Standards Institute (CLSI). Principles and procedure for blood culture. Approved guidelines. Wayne: CLSI M47-A; 2007.

10. Cockerill FR, Wilson JV, Vetter EA, et al. Optimal testing parameters for blood cultures. Clin Infect Dis 2004;38:1724-30.

11. Comitato Linee Guida della Società Italiana di Urologia. Raccomandazioni in tema di diagnosi, trattamento e profilassi delle infezioni delle vie urinarie. 2015. Available from: http://www.siu.it/files/uploads/Linee Guida SIU UTI 2015.pdf

12. Conti A, De Rosa R. Quality Assurance dell'emocoltura. RIMeL/IJLaM 2008;4:36-44.

13. De La Rubia-Ortí JE, Verdu-Trescolí G, Prado-Gascó V, et al. Contamination rate of blood tests and its determining factors. Acta Paul Enferm 2014;27:144-50

14. Durmaz G, Aydinli A, Kiremitci A, et al. Optimum detection times for bacteria and yeast species with the BACTEC 9120 aerobic blood culture system: evaluation for a 5 -year period in a Turkish University hospital. J Clin Microbiol 2003;41:819.

15. Dwivedi S, Bhalla R, Hoover DR, Weinstein MP. Discarding initial aliquot of blood does not reduce contamination rates in intravenous-catheter-drawn blood cultures. J Clin Microbiol 2009;47:2950.

16. Eschira S, Schlaeffer P, Hyam E, et al. Reduction of blood culture contamination rate by an educational intervention. Clin Microbiol Infect 2006;12:818-21.

17. Yu FL, Lin MH, Lee JC, et al. Comparison of antimicrobial susceptibility testing of isolates from blood cultures by direct inoculation method and PHOENIX. J Biomed Lab Sci 2011;23:23-8.

18. Fontana C, Arena F, Argentieri M, et al. Infezioni del torrente circolatorio. Proposta di Percorso Diagnostico. XXXVIII Congresso Nazionale AMCLI - Stresa, 5-8 ottobre 2008 Revisione: settembre 2014.

19. Garcia RA, Spitzer ED, Beaudry J, et al. Multidisciplinary team review of best practice for collection and handling of blood culture to determine effective interventions for increasing the yield of true-positive, reducing contamination, and eliminating false-positive central line associated bloodstream infections. Am J Infect Contr 2015;43:1222-37.

20. Goglio A, Nicoletti P, Indagine nazionale sulle metodiche per emocoltura in Italia. Microbiol Med 2004;19:1-13.

21. Hall KK, Lyman JA, Updated review of blood culture contamination. Clin Microbiol Rev 2006;19:788-802.

22. Hall RI, Domenico HJ, Self WH, Hain PD. Reducing the blood culture contamination rate in a pediatric emergency department and subsequent cost saving. Pediatrics 2013;131:292.

23. Hashemizadeh Z, Bazargani A, Davarpanah MA. Blood culture contamination in a neonatal intensive care unit in Shiraz, Southwest-Central Iran. Med Princ Pract 2011;20:133-6.

24. Karacan C, Erkek N, Senel S, et al. Evaluation of urine collection methods for the diagnosis of urinary tract infection in children. Med Princ Pract 2010;19:188-91.

25. Kubic MJ, Mc Carter YS. Controversies in the diagnosis of urinary tract infections. Clin Microbiol Newsl 2012;34: 185-91.

26. LaRocco MT, Franek J, Leibach EK, at al. Effectiveness of preanalytic practice on contamination and diagnostic accuracy of urine cultures: a laboratory medicine best practice systematic review and meta-analysis. Clin Microbiol Rev 2016;29:105-ì7.

27. Loonen AJ, Jansz AR, Stalpers J, et al. One valutation of three processing methods and the effect of reduced culture times for faster direct identification of pathogens from bact/alert blood cultures by MALDI-TOF. J Clin Microbiol Infect Dis 2012; 31:1575-83.

28. Marschall J, Mermel LA, Fakih M, et al. Strategie per Prevenire le infezioni ematiche associate alle linee centrali negli ospedali per pazienti acuti. Aggiornamento 2014. Infect Control Hosp Epidemiol 2014;35.

29. Martinez RM, Bauerle ER, Fang FC, Butler-Wu SM. Evaluation of three rapid diagnostic methods for direct identification of microorganisms in positive blood cultures. J Clin Microbiol 2014;52:2521.

30. Murillo TA, Beavers-May TK, English D, et al. Reducing contamination of peripheral blood culture in a pediatric emergency department. Pediatr Emerg Care 2011;10:918-21.

31. Nilsson K, Grankvist K, Juthberg C, et al. Deviations from venous blood specimen collection guideline adherence among senior nursing students. Nurse Educ Today 2014;34:237-42.

32. Ntusi N, Aubin L, Oliver S, et al. Guideline for the optimal use of blood cultures. SAMJ 2010;100.

33. O'Grady NP, Alexander M, Dellinger EP, et al. Guidelines for the prevention of intravascular catheter-related infections. MMWR 2002;51:1-29.

34. Palese A, Battistig P, Garlatti I, Scarparo C. La prevenzione della contaminazione delle emocolture. Assistenza Infermieristica e Ricerca 2010:192-7.

35. Park WB, Myung SJ, Oh MD, et al. Educational intervention as an effective step for reducing blood culture contamination: a prospective cohort study. J Hosp Infect 2015;91:111-6.

36. Ramirez P, Gordon M, Cortes C, et al. Blood culture contamination rate in an intensive care setting: effectiveness of an education-based intervention. AJIC 2015;43:844-7.

37. Regione Autonoma Friuli Venezia Giulia. Linee guida regionali per la gestione delle infezioni delle vie urinarie, 2014. Available from: https://www.regione.fvg.it/rafvg/export/sites/default/ RAFVG/salute-sociale/sistema-sociale-sanitario/FOGLIA25/ allegati/09122014_LG_IVU_ott_14.pdf

38. Richter SS, Beekmann SE, Croco JL, et al. Minimizing the workup of blood culture contaminants: implementation and evaluation of laboratory-based algorithm. J Clin Microbiol 2002:40:2437-44.

39. Schneeberger C, Heuvel ER, Erwich JJ, et al. Contamination rates of three urine-sampling methods to assess bacteriuria in pregnant women. Am Coll Obstet Gynecol 2013;121:299-305.

40. Servizio Sanitario Regionale Emilia-Romagna. Infezione delle vie urinarie nell'adulto. Linee guida regionali, 2010. Available from: http://assr.regione.emilia-romagna.it/it/servizi/pubblicazioni/dossier/doss 190

41. Skvarc M, Stubljar D, Rogina P, Kaasch AJ. Non-culture-based methods to diagnose bloodstreaminfection: does it work? Eur J Microbiol Immunol 2013;2:97-104.

42. Valenstein P, Meir F. Urine culture contamination: a college of American pathologists q-probes study of contaminated urine cultures in 906 institutions. Arch Pathol Lab Med 1998;122:123-9.

43. Van der Velden LB, Mouton JM, Sturm PD. Clinical impact of preincubation of blood cultures at $37^{\circ} \mathrm{C}$. J Clin Microbiol 2011;49:275-80.

44. Velasco R, Fernández JL, Campo MN, Puente S. Evalutation of hemocolture extraction technique in an emergency department: nursing staff self-perception and reality. J Emerg Nurs 2014;40:36-8.

45. Vitrat-Hincky V, Francois P, Labarère J, et al. Appropriateness 
of blood culture testing parameters in routine practice. results from a cross-sectional Study. Eur J Clin Microbiol Infect Dis 2011;30:533.

46. Youssef D, Shams W, Bailey B, et al. Effective strategy for decreasing blood culture contamination rates: the experience of a Veterans Affairs Medical Centre. JHI 2012;81:288-91.

47. Yu Lau A, Wong SN, Yip KT, et al. A comparative study on bacterial cultures of urine samples obtained by clean-void technique versus urethral catheterization. Acta Pediatrica 2007;96:432-6. 